\section{ASPIRACIONES PROGRESISTAS, DISPOSITIVOS CONSERVADORES: MULTICULTURALISMO, NUEVA MUSEOLOGİA Y PAULO FREIRE}

PROGRESSIVE DISCOURSES, CONSERVATIVE

DEVICES: MULTICULTURALISM, NEW MUSEOLOGY AND PAULO FREIRE

\author{
Glauber de Lima \\ Universidade Federal de Goiás, UFG (Brasil) \\ ORCID: 0000-0001-5332-6731 \\ delimaglauber@gmail.com
}

Para citar este artículo:

De Lima, G. (2020). Aspiraciones progresistas, dispositivos conservadores: multiculturalismo, nueva museología y Paulo Freire. Commons. Revista de Comunicación y Ciudadanía Digital, 9(2), 159-185. http://doi.org/10.25267/COMM0NS.2020.v9.i2.05

Fecha de recepción: 27/04/2020. Fecha de aceptación: 06/06/2020

\section{Resumen}

Este artículo aborda el uso político-discursivo del pensamiento de Paulo Freire por parte de la nueva museología en Brasil. Aquí, se sostiene que este segmento del campo de la museología representa un proyecto multicultural y desarrollista, y que afirma estar asociado epistemológicamente con las ideas de Paulo Freire para que su identidad sea adecuada a los discursos inclusivos. Esta discusión se basa en análisis textuales y en la economía política, y se centra en los textos museológicos y sus respectivos efectos a través de las políticas culturales. Se destaca el hecho de que este enlace enfatiza la perspectiva dialógica de Freire, pero, a su vez, eclipsa su crítica materialista. Como consecuencia, las renovadas perspectivas museológicas han generado iniciativas con el léxico freiriano cuyas prácticas están en línea con la ética liberal. En este sentido, tenemos aquí la intención de iluminar esta paradoja para reflexionar sobre los efectos en la ciudadanía derivados de esta política cultural.

\section{Palabras clave}

Multiculturalismo, desarrollo, museos, Paulo Freire, política cultural

\begin{abstract}
This paper addresses the political-discoursive use of Paulo Freire's by the new museology in Brazil. This latter is an approach which embodies a multicultural project to museums. The core argument is that it is a liberal formulation which instrumentalises Freire's ideas to seems progressive. The discussion grounds itself on textual analyses and political economy. As such, it examines Paulo Freire's texts, the rhetoric of the Brazilian cultural policy for museums, and museological practices. From these issues, it highlights that this museological view adopted Paulo Freire's dialogical perspective but, conversely, it overshadowed its materialist criticism. New museology has used Freirian lexicon to define its practices, albeit they have taken form by liberal ethics. In this sense, this work stresses this paradox to point out its effects on the current Brazilian debate on culture and citizenship.
\end{abstract}

\section{Keywords}

Multiculturalism, development, museums, Paulo Freire, cultural policy 


\section{Introducción}

Este artículo aborda el uso que la nueva museología hace del pensamiento de Paulo Freire para dar un sentido liberador al proyecto multicultural y desarrollista que este representa. A mediados del siglo pasado, surgió en los círculos interesados una actuación más progresista de los museos, un entendimiento en sintonía con los imperativos liberadores de Freire. Esta concepción, en gran medida, fundamentó una perspectiva acuñada como nueva museología, que se describe como un segmento comprometido con una agenda popular-democrática para estos espacios de memoria.

Sin embargo, sus prácticas desentonan con la crítica producida por Paulo Freire, especialmente en lo que respecta a su forma de tratar las contradicciones que constituyen las relaciones de opresión. Por ello, lo que interesa aquí son tanto la forma en la que se estructuran los términos de esta brecha, como los efectos de una instrumentalización que la asocia a un multiculturalismo y a una lógica específica de la economía de la cultura.

El análisis que se utiliza en este estudio articula elementos de intertextualidad y economía política, debido tanto al interés por reasignar los términos presentes en el pensamiento de Paulo Freire, como en sus efectos en las políticas culturales brasileñas. Esto implica tener en cuenta tanto la producción textual del ámbito de los museos que invoca la pedagogía freiriana como guía, como los elementos de políticas públicas culturales que consignan acciones en la línea del proyecto de la nueva museología.

Esta discusión tendrá como punto de partida la lógica actual de instrumentalización de la cultura, la cual orienta el papel que los museos asumen en la contemporaneidad y los discursos que adoptan para legitimar sus políticas. A continuación, se profundizará en la dinámica de la cultura de las políticas de desarrollo, con la correspondiente posición de Paulo Freire en este debate. Dada la declarada filiación Freire/museos basada en principios de transformación y mejoría de la sociedad, la forma en que tales sentidos se estructuran en cada uno de los polos 
de esta relación será objeto de discusión en las secciones siguientes. Finalmente, se analizará un caso específico en el contexto brasileño, donde se materializan todas las contradicciones que serán tratadas en este estudio.

Sin embargo, se entiende que es importante anticipar tres significados que ocupan un lugar central en esta discusión: liberalismo, desarrollismo y progresismo. Aquí, el sentido de liberal es equivalente tanto a la ética de la primacía del interés privado como a la libre empresa, así como a la concepción que converge especialmente de lo que se critica en el pensamiento de Paulo Freire. Sobre el desarrollismo, hace referencia al debate a escala global sobre las políticas de desarrollo para dicho tercer mundo, y que no atacó a las razones de la desigualdad. Por fin, la progresividad implica una comprensión ético-política comprometida con el cambio de la sociedad basada en una agenda que, históricamente, se ha ubicado con mayor frecuencia en el campo político de la izquierda (Miller \& Yúdice, 2002).

Al final de este artículo se pretende haber demostrado cómo la aplicación del pensamiento de Paulo Freire está en sintonía con la razón neoliberal para la cultura, donde los sentidos se dislocan en pro de la producción de legitimidad de prácticas conservadoras. Más aún, este tipo de operación socava la pujanza del pensamiento de Freire al colocarlo al servicio de la instrumentalidad multicultural, y la imprecisión que se desprende de la forma en que esta operación se materializa - una pedagogía multiculturalista que desentona con la propia pedagogía de la autonomía-, es parte del conjunto de factores que impulsaron recientemente la crítica reaccionaria que atribuye a Paulo Freire responsabilidad por las contradicciones en el modelo de ciudadanía vigente.

\section{Instrumentalidad y multiculturalismo}

Heidegger (2007) elaboró una concepción de la técnica definida como un modo de pensar que considera la naturaleza como recurso, algo que existe como medio para alcanzar una finalidad. Su argumento es que esta forma de concebir el mundo invisibiliza la esencia de las cosas, en tanto que los únicos sentidos posibles 
que pueden adquirir conocimiento sobre la vida son aquellos de naturaleza instrumental. Esta instrumentalidad, consecuentemente, involucra a la cultura, y es a esta posibilidad a lo que George Yúdice (2006) se refiere en su discusión sobre la naturaleza conveniente de la cultura en la contemporaneidad.

Tal conveniencia incide en el hecho de que la cultura haya adquirido un sentido de insumo crucial para la mejoría de la sociedad, lo que le garantiza un lugar estratégico en la resolución de problemas que otras áreas de la vida humana no alcanzaron en tiempos anteriores — tales como lo social y lo económico-. Esta condición es algo que puede ser percibido a partir de su actual cercanía con bancos, agencias de desarrollo, movimientos sociales y otros agentes locales y globales de gran relevancia. Son frecuentes los esfuerzos, tanto globales como locales, de la cultura en producir experiencias de desarrollo económico, empoderamiento y mediación de conflictos.

Es en este contexto, y bajo esta lógica de conveniencia, que los museos vienen multiplicándose tanto a nivel global como en Brasil (Yúdice, 2006). En las últimas décadas, el número de instituciones ha aumentado, y se han diversificado sus formas de relacionarse con las personas. Son bastante comunes las discusiones que actualizan tipologías de museos, conceptos, o tratan de clasificar experiencias antes consideradas heterodoxas como nuevas formas de actuación del museo (Brulon, 2019). La directriz que orienta este despliegue es fundamentalmente su instrumentalidad, y sus modos de hacer vienen dictados, cada vez más, por aquello que los hace tácticamente capaces de promover sus intereses.

Sin embargo, la efectividad de algunos usos encuentra obstáculos en el aura conservadora que históricamente se creó en torno a su lógica institucional. Así, como Tony Bennett (2013) sugiere, estas instituciones surgen en la modernidad como instrumentos en operaciones de regulación y gobierno de los individuos. $\mathrm{Su}$ racionalidad política consiste en asegurar que los sujetos se conviertan en ciudadanos dóciles y aptos para vivir en armonía con el orden hegemónico. Incluso con el reciente auge de imperativos democratizantes, los museos aún mantienen esta identidad política, lo que produce una brecha estructural entre su aspiración 
por ser universalizantes, en términos de acceso y representación, por un lado, y su naturaleza disciplinaria, regulatoria y consecuentemente excluyente de lo diverso, por el otro (Miller \& Yúdice, 2002).

En este sentido, los proyectos que buscan atribuir a estas instituciones una nueva aura, más progresista, buscan construir retóricamente otra que, discursivamente, enmascare esta discrepancia. Es el caso de un movimiento designado como nueva museología, que pretende estar afiliado con el pensamiento de Paulo Freire. Este proyecto consiste, básicamente, en un despliegue de multiculturalismo en todos sus tonos liberales convencionales, así como del desarrollismo cultural practicado por la Unesco desde mediados del siglo pasado. Según sus enunciados, los museos renovados deberán convertirse en instrumentos del cambio social, mediante una integración museo-comunidad, en vectores de producción a partir de políticas de desarrollo local (Duarte, 2014).

Tanto el multiculturalismo como el desarrollismo que fundamentan la nueva museología están, en un primer momento, en sintonía con el proyecto de Freire. Mientras que el primero remite a una política de convivencia armónica con la diferencia cultural (en términos de la declaración universal para la diversidad cultural), el segundo intenta revestirla (bajo la denominación de patrimonio) de la condición de recurso económico en pro de las comunidades. No por casualidad, tal planteamiento tuvo gran éxito entre los agentes interesados en una actuación progresista en los museos, mientras que la pretendida filiación sellaba la integralidad multicultural de los museos como posible derivación de una pedagogía liberadora. Sin embargo, este conjunto de cuestiones presenta desviaciones muy significativas de elementos que son primordiales en una pedagogía crítica como la de Paulo Freire.

El primero de ellos se refiere a la naturaleza inclusiva de estas políticas, que transparentan una forma de regulación (gubernamentalidad ${ }^{1}$ ) no interesada en la superación de las desigualdades estructurales señaladas en la pedagogía freiriana. Como afirma Jacques Derrida (2001), no existen integración y hospitalidad incondicionales hacia el extranjero, lo que implica el hecho de obligarnos a

1. La gubernamentalidad es una formulación de Michel Foucault que describe una racionalidad de gobierno típica de las democracias liberales. Esta se basa en una lógica no coercitiva, en el autogobierno de los individuos, y en la producción de una lealtad entre los individuos y el orden hegemónico mediante la cultura (Miller \& Yúdice, 2002). 
admitir que hay algo más, además de benevolencia, en el discurso de la diversidad: las cuestiones de control y gobierno. Tales expedientes de regulación se hacen visibles en la relación que se constituye mediante la ciudadanía, donde el sujeto que se convierte en ciudadano debe cumplir las condiciones requeridas para beneficiarse de este nuevo status.

Más allá de eso, e igualmente bajo el argumento de la sostenibilidad, que supuestamente debe ser la fortaleza natural del patrimonio en el impulso desarrollista de la Unesco, el reconocimiento de la diferencia también efectúa una maniobra de regulación, mientras que las políticas de patrimonialización ofrecen la esperanza de un cambio social por la sostenibilidad, pero se materializan frecuentemente con fuertes matices de precariedad económica, en perjuicio de las comunidades (Lima \& Neto, 2019).

El segundo problema se refiere a la propia brecha que la idea de diversidad establece en relación con una pedagogía que se define como crítica de las relaciones de poder. La praxis pedagógica multiculturalista, que se alinea con lo que la Unesco preconiza, está interesada en producir un sujeto que tolere identidades culturales que no son la suya, así como que se abstenga de comportamientos tenidos como prejuiciosos, lo que resultaría en un individuo digno, portador de una ética (estrechamente asociada al ethos liberal) que lo habilita para la convivencia democrática.

Con todo, a pesar de estos bien intencionados efectos, el multiculturalismo se abstiene de problematizar con la debida profundidad la producción social de la identidad y de la diferencia. En esas condiciones, ambas cuestiones se asumen como elementos favorables, autorreferentes y autónomos; y como afirma Tomaz Tadeu da Silva (2000: 1): "en la perspectiva de la diversidad, las diferencias de identidad tienden a ser naturalizadas, cristalizadas y establecidas como esenciales. Se consideran datos o hechos de la vida social ante los cuales se debe tomar posición". 
Sin embargo, esta perspectiva suprime el hecho de que ambas son resultados de procesos culturales, y que se producen en lugar de venir dadas, siendo la diferencia el insumo manejado políticamente, con tal de constituir identidades seleccionando, excluyendo y jerarquizando posibilidades de Ser. Consecuentemente, nunca hay inocencia política en el sujeto multicultural tolerante, así como en el Otro idealizado que debe ser respetado. Ambos forman parte de una política de la diferencia que no puede ser ignorada en un proceso que se define como liberador, porque es ella precisamente el terreno en que se constituyen culturalmente las profundas relaciones de opresión que Freire está interesado en romper.

En este sentido, ante estas contradicciones de base, lo que se quiere demostrar aquí es que la nueva museología promovió una rearticulación de elementos que configuran el pensamiento de Paulo Freire, expresándolo en total sintonía con un proyecto multicultural y desarrollista.

\section{Nueva museología y desarrollo}

La génesis de la nueva museología se dio a partir de un evento realizado en Santiago de Chile, en el año 1972. Tal acontecimiento fue dirigido por el Consejo Internacional de los Museos -ICOM, el organismo de la Unesco para los museosy consistió en una mesa redonda que pretendía estar interesada en armonizar estas instituciones con las demandas políticas de aquel contexto. Sus impulsores planearon tener a Paulo Freire como gran mediador de los debates, y esperaban que él pudiese influir en el campo de los museos a partir de sus elaboraciones sobre lo que debería ser el respectivo papel político de estos espacios (Varine, 2000).

De acuerdo con Hughes de Varine, entonces pesidente del ICOM, Paulo Freire fue formalmente invitado a participar de la Mesa Redonda de Santiago, pero su nombre fue rechazado por el representante del gobierno brasileño en la Unesco a causa de su posición crítica hacia el gobierno de este país (Instituto Brasileiro de Museus, 2012a). Varine es el fundador de la narrativa que asocia directamente la renovación de la museología al pensamiento freiriano, y afirma 
que su no participación en la mesa está lejos de significar una discontinuidad en la construcción de esta filiación. Algo que se pondría de manifiesto en el concepto de museo que se desarrollaría a partir de este evento, habiendo de ser este un experimento que integrara instituciones y comunidades, y que da centralidad a un dialogismo en su actividad, lo que aproximaría una experiencia así al tipo de educación que preconiza la pedagogía liberadora.

Varine (1996) justifica incluso su aproximación a Paulo Freire como un desdoblamiento de sus correspondientes actuaciones en sectores progresistas ligados a la Iglesia Católica, así como por ver en Freire un apoyo teórico-político a sus aspiraciones (y las de otros agentes) de superar las barreras de principios y métodos de conversión del catolicismo con los cuales tenían que lidiar. Tales pretensiones incluirían incluso el agregar nuevos temas a la agenda de cooperación para el desarrollo, la cual limitaba el contexto de la Unesco, en especial con las perspectivas enfocadas en la acción comunitaria. Este enredo, que involucra a la Unesco, al desarrollo, los museos y el catolicismo progresista, sugiere en gran medida los principios que guían la encomienda que Varine va a asumir en relación con la articulación Paulo Freire/nueva museología.

La Unesco ya venía ejerciendo desde la posguerra una gran influencia global en los debates sobre desarrollo y cultura. Su propia creación le asignaba ya la responsabilidad de implementar una política cultural que materializase los principios presentes en la Declaración de los Derechos Humanos. A mediados de la década de 1950, se consagró un importante acuerdo en favor de los países del Sur global al definir que la propiedad sobre la cultura residía en su origen, lo que tenía un impacto importante en el campo de los museos y del patrimonio. En las décadas siguientes, la mayoría de los países que componían la Unesco pertenecían al entonces denominado tercer mundo, y esto implicó la adopción de una agenda que la transformó en la respuesta culturalista de esas naciones al poderío económico y político de los países más ricos.

A mediados de la década de 1970 se sucedieron una serie de estudios y conferencias críticas con el modelo según el cual se estructuraba el orden global, siendo la Mesa Redonda de Santiago uno más de estos eventos. Con todo, la reacción del 
Norte Global, y el correspondiente avance del neoliberalismo en la década de 1980, resquebrajó esta pujanza tercermundista y forzó una rearticulación de los sentidos de los temas que ocupaban un lugar central en su agenda (Miller \& Yúdice, 2002).

Tal agenda se desarrolló en relación a los museos por medio de una articulación que asocia patrimonio, comunidades y desarrollo local. Fue en este contexto que surgió un célebre concepto museológico - que estuvo en las raíces de la nueva museología- que es el de ecomuseo, según el cual el foco de la experiencia museológica dejó de ser la constitución, preservación y comunicación de colecciones, y pasó a ser la comunidad en sí, la vida de las personas integradas a lo local, que pasa a constituir la sustancia misma de lo que se llama patrimonio. Hughes de Varine (2013) fue un gran entusiasta de esa posibilidad de musealización a causa de su dinámica favorable en experiencias de desarrollo, por haber trabajado él mismo como consultor y producido una metodología sobre el modo de optimizar la condición de recurso del Patrimonio. Esta disposición, que articuló memoria, territorialidad, comunidad, sostenibilidad e instrumentalización de la patrimonialización fomentó el debate sobre desarrollo a lo largo del avance de la nueva museología en las décadas siguientes. A partir de entonces, la museología pasó a mirar y reconocer otras experiencias heterodoxas de musealización, tales como los museos de favela.

En Paulo Freire, el debate sobre desarrollo también se hacía presente, aunque los términos en los cuales él formula sus concepciones se diferencien significativamente del enfoque economicista de la Unesco. Tanto la directriz para el desarrollo en América Latina conducida por la Comisión Económica para América Latina y el Caribe de la Organización de las Naciones Unidas (CEPAL), como sus despliegues entre la intelectualidad brasileña (como el que se produjo en el Instituto Superior de Estudios Brasileños [ISEB]) influyeron en su formación. Sin embargo, las propuestas que apuntaban hacia la superación del subdesarrollo abordaban muy poco, o casi nada, los aspectos que estructuraban la desigualdad. Es especialmente a partir de las formulaciones de Álvaro Vieira Pinto sobre el papel transformador atribuido a la Cultura, que la concebía como una manifestación capaz de desencadenar un proceso de transformación con fuerte participación popular, que Freire se integrará más directamente a esta cuestión (Martini, 2009). 
Freire se distanciaba del pensamiento convencional y corriente sobre el desarrollo a partir de dos cuestiones básicas. La primera de ellas consistía en su resistencia a asumir la naturalización, como se sugería en el referido debate, de la proletarización del trabajador en los procesos de desarrollo. Tal concepción estaba presente en la lógica industrializadora y urbanizadora inherente al ISEB, que ubicaba a los trabajadores en esa condición estática, algo que chocaba fuertemente con el anhelo reformista de Freire, especialmente a causa de su aspiración de que las comunidades campesinas tuvieran un papel protagonista. La segunda corresponde a su propio perfil de formación, que no se estructuraba a partir de la economía, como el de los pensadores de la CEPAL y el ISEB. Esto le permitió desplazar el centro de la cuestión de la razón económica hacia la humanización, concibiendo lo que habría de ser la idea del desarrollo como la superación de las contradicciones por medio de una educación liberadora. Con esto, su formulación difiere tanto de los modelos que lo anteceden como de los otros que se dieron a continuación, dado que estos se fundamentaron en la reproducción de las contradicciones que originan las relaciones de opresión.

\section{El cambio social y los museos}

Desde Santiago hasta la actualidad, el ICOM se ha dedicado a rubricar una ciencia de los museos que refleje la integralidad como uno de sus rasgos epistemológicos (Brulon, 2019). En Brasil, las proposiciones que teorizan sobre la museología, y que están directamente interesadas en el trabajo de los museos con las comunidades, han reiterado que esta formulación está en el núcleo de lo que más prosperó en las prácticas museológicas más progresistas, y en algunos casos con una mención directa al legado de Freire como una gran influencia (Scheiner, 2012; Santos, 2014; Chagas et al., 2014).

Sin embargo, lo que se percibe en medio de todas estas formulaciones y políticas es que el léxico que ellas comparten ha sido manejado en sentidos distintos $y$, a veces, antagónicos a lo que está presente en el trabajo de Paulo Freire. Esto involucra una discordancia entre los sentidos de términos tales como desarrollo, emancipación, humanización y participación. En todos los casos, los usos 
en la nueva museología han incorporado elementos del multiculturalismo/ desarrollismo en los términos ya referidos. Esto implica decir que este segmento museológico ordenó discursivamente su identidad político-epistemológica como un proyecto en sintonía con la pedagogía freiriana, pero concibiéndola a partir de sentidos que son ajenos a ella.

Esta (re)designación de sentidos, a fin de producir una totalidad que responda con sus nuevas verdades a una urgencia contemporánea, está lejos de ser una particularidad del campo de los museos. Algunos trabajos sobre el neoliberalismo en el campo educacional, tales como los de Roberto Leher (2012), dejan claro cómo esta ingeniería discursiva se da con gran efectividad en otras áreas. Además, estas evidencian que no es raro que la construcción de la difusión y legitimidad de un discurso hegemónico pase por su elaboración en medio de terminologías y estrategias que tienen un origen progresista y transformador.

En el caso de la museología, la urgencia reside en la necesidad de potenciar una labor inclusiva y desarrollista por medio de los museos, borrando sus contradicciones. Tal enfoque discursivo obra en favor de una política cultural multiculturalista, que necesita declararse democrática e interesada en un cambio social para ser legítima y eficaz, pero que obra para producir ciudadanos comprometidos con el orden hegemónico, sin desestabilizarlo. Esto implica decir que la relación entre la nueva museología y la pedagogía liberadora es fundamentalmente retórica, mientras que sus prácticas carecen del contenido revolucionario que Paulo Freire concibió para lo que sería una praxis transformadora.

Para que queden más claros los términos de esta articulación, es importante observar qué elementos están engendrados en esta designación. Básicamente, el pensamiento de Paulo Freire puede entenderse a partir de dos ejes que lo fundamentan. El primero de ellos consiste en su concepción de cómo se establecen las desigualdades, lo cual está organizado bajo una base histórico-materialista que vislumbra en las contradicciones de la relación capital-trabajo una directriz estructural de producción de la opresión. El segundo se refiere a la forma de superar lo que se deriva de esas contradicciones y consiste esencialmente en 
su concepción de la praxis como dialógica, donde se ha de construir material y horizontalmente como un proceso de humanización que involucra a un agente (es el profesor quien mejor personifica esa función) y un Otro a ser humanizado. 0 sea, las contradicciones del capital/trabajo y el dialogismo son las dos bases ético-políticas de la concepción de Paulo Freire acerca de cómo se genera la deshumanización y cómo debe desarticularse.

El argumento aquí utilizado es que la nueva museología apenas se relaciona con la naturaleza dialógica del pensamiento freiriano, en detrimento de su crítica materialista. Es la pujanza inclusiva del dialogismo, que sugiere funciones sin jerarquías entre los participantes en una experiencia de diálogo, y que es seductor para el Otro oprimido porque lo considera, ahora, digno de esta posibilidad de interacción en términos igualitarios, lo que moviliza el interés del campo museístico. Por consiguiente, al declarar su compromiso con la concepción liberadora de Freire, esta replantea el propio sentido de lo que viene a ser su pedagogía, dando centralidad al dialogismo e invisibilizando su contenido revolucionario y crítico del capital.

Al contrario de lo que esta retórica sugiere, tal cambio social se posicionaría mejor en los términos de un multiculturalismo liberal, donde la visibilidad y la voz no son conquistas igualmente acompañadas por cambios estructurales en aquello que produce la opresión. Esto corresponde a producir una organización social descentralizada, en la que predomine un sujeto autónomo, que crea en la eficacia de sus capacidades individuales y de su libertad como preceptos determinantes para su prosperidad, y guiado por una sustancia ética que articula morales contradictorias de consumo y ciudadanía (Miller \& Yúdice, 2002). Esta reingeniería discursiva, que obstruye la pujanza revolucionaria del pensamiento de Paulo Freire para expresarlo como base teórico-política para una economía política de la diversidad, se hace aún más evidente mediante una mirada más detallada sobre las bases filosóficas que articulan lo que habría de ser su proyecto transformador. 


\section{El cambio social en Paulo Freire}

En vez de emprender una ya esbozada tarea de identificar filosóficamente el pensamiento de Paulo Freire, sus formulaciones se discutirán aquí de una forma más simple, tratándolo relacionado a la idea de cambio en sus concepciones. Esto equivale a tratar de abarcar algunos aspectos más urgentes para los intereses de este trabajo, que involucran tanto el modo en el que Freire concibe la constitución del sujeto o la estructuración de las desigualdades, como el campo en el cual se dará la praxis con la cual él (el sujeto) construirá su humanización. Esto se realizará por medio de lo que él presentó en Acción cultural para la libertad y Pedagogía del oprimido.

La fenomenología de Hegel ejerció gran influencia en el ideario freiriano, algo que se evidencia en el lugar que concede a la relación entre consciencia y conocimiento en la constitución del sujeto. En Freire (1987), existe una correspondencia absoluta entre ser y saber, donde experiencia y conciencia forman una sustancia única que ofrece la existencia del ser, y que representa su plena comprensión de su lugar en el mundo. En Hegel (1992), este proceso es una construcción, involucra la temporalidad, es histórico y, por consiguiente, dialéctico. Más aún, implica también una dimensión divina, en tanto que el conocer significa para el sujeto encontrar una verdad que ya existe en sí, y que tendría que haber sido sembrada por Dios. Sin embargo, este encuentro consigo mismo y con el mundo involucra un aprendizaje, por ser producto de un proceso que se construye temporalmente, donde el sujeto capitaliza conocimiento, y que habrá de darse inevitablemente en lo que él define como experiencia.

Paulo Freire concibe el sentido de existir en líneas bastante similares. Para él, hay en el núcleo del individuo una naturaleza que tiende a la instrucción y las virtudes, siendo la existencia el desarrollo de esas potencialidades, donde al sujeto lo guía una permanente necesidad de "ser más" (Freire, 1987: 48). Esta constante búsqueda es la que produce la humanización, es una lucha dialéctica en la que él se transforma a sí mismo y a los objetos de su conocimiento (mientras es transformado por ellos). 
Existe en Freire un apriorismo cristiano ${ }^{2}$ que también vislumbra, como en Hegel, un sentido transcendental en esta esencia de autoconocimiento del individuo. Sin embargo, este transcendentalismo está, en su ideario, articulado con un sentido político; articulación esta que encuentra en la educación el expediente tópico de construcción de la humanización.

En la relación entre ser, conocer y educación, los matices de lo que viene a ser la transformación quedan más claros en Freire. Al mismo tiempo que él considera lo que constituye el sujeto/mundo plasmado a partir de una cuestión transcendente y apriorística, Paulo Freire abarca también la naturaleza política de los que van a ser los obstáculos para el proceso de humanización. Él recurre a Karl Marx para explicar las contradicciones de la relación capital-trabajo en la constitución de la deshumanización, y da importancia a que el sujeto no perciba los términos que las estructuran, siendo esto factor fundamental para que se mantenga la estabilidad y reproducción del orden (Freire, 1981). Tal concepción, que no diferencia empeños diversos en términos de realidad objetiva y subjetiva, percibe la concienciación como proceso ético-político clave para un cambio que represente la superación de la opresión. En esta, apenas por una praxis comprometida con la humanización de los hombres - o sea, que desvele el mundo de la opresión y permita al sujeto enfrentarlo para cambiarlo- es que se hace posible una existencia en la que saber y ser sujeto de sí, son partes de la misma sustancia.

De aquí que Freire hable de una educación que se enfoque a la autonomía, puesto que es un recurso excepcional para el cultivo de virtudes, dado que estas serán las que permitan al sujeto emanciparse de lo que la opresión le destina. Es en este proceso educativo, que alcanza su plenitud dentro de una dinámica dialéctica y materialista que involucra sujeto y mundo, que se da colectivamente, y que Freire define como revolucionario, donde ha de constituirse la metamorfosis social en la cual las contradicciones que la estructuran deberán ser superadas.

2. Paulo Freire afirmó que había un apriorismo en su pensamiento debido a su creencia en la existencia de Dios. Esto implicaba que estaba aceptando que había algo fuera de la historia y la experiencia, lo que constituía una contradicción con el pensamiento de Marx. Sin embargo, Freire entendió que Marx era una referencia fundamental para la crítica política que debería hacerse al neoliberalismo. Aunque esta contradicción le impidió llamarse marxista, fue con Marx donde construyó su comprensión de la realidad (Nogueira, 1997). 
Siendo así, el cambio social en Freire posee no solamente un fundamento político y subjetivo, que equivale a incluir las raíces de la desigualdad dentro de la relación referida. Su planteamiento retiene, esencialmente, un elemento ético que hace imperativo un quehacer, un actuar, en el sentido de superar lo que suprime esa toma de posición, que es precisamente lo que él está designando como opresión. Freire se vuelve recurrentemente hacia el liberalismo democrático como gran objeto de su crítica, no siendo raras sus tentativas de argumentar en pro de diferenciar su proyecto de cualquier cosa que se asemeje a las políticas inclusivas de la ciudadanía liberal (Freire, 1987). Su crítica hace muy evidente una preocupación con la lógica que refiere la concesión de algunos derechos - bajo el signo de la inclusión- sin atacar las raíces de la opresión, y como forma de actualizar la estabilidad social que la hace posible.

Tal posicionamiento anticipa el problema inherente a un uso del discurso dialógico disociado del materialismo. Freire concibe el diálogo como fenómeno intrínsecamente humano, y la palabra - su elemento básico- como una unidad que agrega una doble posibilidad de acción-reflexión. A una educación como práctica de libertad cabe extender a todos la posibilidad de pronunciamiento pleno de la palabra, de una comunicación en la cual sentido y acción estén plenamente imbricados en lo que todos declaran, y no solamente bajo el dominio de quien oprime. El sentido de diálogo en Freire, por consiguiente, traduce muchas veces en lo que él llama amor - un compromiso absoluto con el Otro (Freire, 1987). El dialogismo habrá de ser la materialización de este espacio de igualdad, libertad y poder acumulado por el Otro en el diálogo, donde los hombres construyen mutuamente su "ser más".

Por lo tanto, no hay en la concepción de Freire una posibilidad de algún desmembramiento que conciba una relación dialógica descomprometida de una praxis transformadora. No hay libertad posible sin una declaración que lleve en sí el sentido de aquello que estructura la desigualdad, y que la transforme en pro de los oprimidos. Es en esta disyunción entre dialogismo y liberación donde radica el punto crítico del rediseño producido por la nueva museología respecto al pensamiento de Paulo Freire, y donde la práctica educativa de concesión de voz al Otro - empoderándolo por medio de su diferencia cultural—, fue transformada en la síntesis de su pedagogía. 
Es precisamente un ejemplo de esta operación discursiva multicultural lo que se analizará en la siguiente sección.

\section{Prácticas conservadoras}

En Brasil, las primeras décadas de este siglo suponen un período de profundización de la lógica que fundamenta las democracias multiculturales (Yúdice, 2006). A partir del primer gobierno del Partido de los Trabajadores —en 2003-, se sistematizó una política pública para la cultura fuertemente amparada en el discurso de la diversidad, y en la instrumentalización del patrimonio y de los museos en pro de iniciativas de inclusión y una economía de la cultura. Esto incidió, más directamente, en la creación de un organismo del Estado concebido especialmente para dedicarse a las políticas orientadas a la esfera de los museos, el Instituto Brasileño de los Museos (IBRAM).

Sus directrices más importantes, plasmadas en la Política Nacional de Museos (Instituto Brasileiro de Museus, 2007), fueron confeccionadas con la participación de muchos agentes de la esfera de los museos y, en algunos de sus principios más básicos, se hace bastante evidente el rasgo freiriano introducido a partir de la nueva museología ${ }^{3}$.

En la definición de sus políticas educacionales (Instituto Brasileiro de Museus, 2018), esta institución, como instrumento de las políticas oficiales de la cultura para los museos, reafirma de manera más explícita el lugar de la pedagogía freiriana en la museología. Más allá de la reproducción de la recurrente narrativa relativa a la mesa de Santiago, y su correspondiente influencia en las formulaciones que se siguieron, Paulo Freire se asocia directamente a las prácticas contemporáneas que se consideran más progresistas:

3. Son ellos el desarrollo de políticas educacionales orientadas hacia el respeto a la diferencia y a la diversidad cultural del pueblo brasileño, el estímulo y apoyo a la participación de museos comunitarios y ecomuseos, el derecho de las comunidades a participar en los procedimientos técnicos y políticos de definición del patrimonio a musealizar, la sustentabilidad del patrimonio cultural sometido al proceso de musealización, y el respeto al patrimonio cultural de las comunidades indígenas y afrodescendientes. 
La Museología Social también está inspirada en la educación popular de Paulo Freire y hoy, por medio del Programa Pontos de Memória, reúne un conjunto de acciones e iniciativas de reconocimiento y valorización de la memoria social, de modo que los procesos museísticos protagonizados y desarrollados por pueblos, comunidades, grupos y movimientos sociales, en sus diversos formatos y tipologías, sean reconocidos y valorizados como parte integrante e indispensable de la memoria social brasileña. (Instituto Brasileiro de Museus, 2018: 19)

Además de aprobar en sus documentos, directrices y premisas, la condición estructurante que la nueva museología atribuyó a Paulo Freire en la esfera de los museos, el IBRAM buscó consagrar iniciativas que alegaban materializar lo que habría de ser una museología liberadora. Precisamente, esto ocurrió con el Premio Darcy Ribeiro de 2008, con el que este organismo reconoció acciones que se presentaban como establecidas en la pedagogía en cuestión, y las celebró como experimentos que simbolizaban el tipo de experiencia educativa y transformadora que se aspiraba a construir.

Una iniciativa contemplada por este premio, en especial, es bastante representativa de las contradicciones y de los efectos políticos de la articulación que se discute aquí. Se trata del "Programa de Formación del Joven Artesano", desarrollada por el Museo del Hombre del Nordeste (MUHNE) en Pernambuco. Este emprendimiento educativo mereció menciones de honor en certámenes nacionales einternacionales sobre prácticas educativas en museos, y se presentaba como una acción de inclusión social, gestada a partir de la alianza con multinacionales, ONGs y gobiernos locales, y que perseguía capacitar a jóvenes como artesanos a partir de cursos de emprendimiento, liderazgo, organización y gestión; alegando estar, con ello, produciendo una experiencia educacional liberadora según los modelos de lo que Paulo Freire preconizaba (Instituto Brasileiro de Museus, 2012b).

Esta acción ocurrió en el período 2005-2011, con una red de núcleos que trabajaban para profesionalizar individuos de entre 14 y 21 años como artesanos. Tales unidades estaban situadas en barrios de la ciudad de Recife, y en el propio museo, y desarrollaron acciones en su zona metropolitana y en el municipio de Araçoiaba, incluyendo a más de 300 jóvenes durante todo este periodo. Se escogió la artesania como práctica central de la acción educativa en razón de su potencial para constituirse como actividad generadora de ingresos, además de ser 
frecuentemente descrito en los archivos de esta acción como una vía de desarrollo creativo en pro de las personas que estaban siendo formadas (Fundação Joaquim Nabuco, 2012).

La metodología utilizada se estructuró a partir de tres ejes: arte/artesanado, producto y desarrollo del individuo, siendo quienes conducían los procesos educativos provenientes de las siguientes áreas: artes (educación), diseño, moda, gestión de negocios, marketing, emprendimiento, psicología, asistencia social y educación patrimonial. Pedagógicamente, las actividades se guiaron por el interés en cultivar un sentido estético entre los jóvenes con centros de manufactura que desarrollaban sus habilidades técnicas —arte/artesanado-y los capacitaba para dar acabado a su trabajo, también estéticamente, con una lógica orientada a su transformación en un producto. Todas estas acciones estaban simultáneamente asociadas con cursos, conferencias y talleres que buscaban calificarlos como emprendedores, donde predominaban discursos sobre gestión y ciudadanía, y en los cuales el sentido de creatividad consistía en una deseada y efectiva habilidad gerencial a ser cultivada en cada sujeto en pro de su sustentabilidad económica (Fundação Joaquim Nabuco, 2010).

Según una de las profesionales vinculadas al programa, la evaluación en una de las unidades permitía percibir el grado de precariedad con que esta producía efectos en términos de sostenibilidad. A lo largo del período de formación (que duraba dos años) se producía una deserción masiva de los participantes, así como su opción por otras actividades económicas más rentables, más estables o de emergencia. Positivamente, en términos materiales, la acción permitió la estructuración de grupos permanentes de artesanos, la comercialización de los productos en espacios privilegiados de venta de artesanado, la formación de una red que involucraba a socios de diferentes esferas, además de la visibilidad que aportaba la participación de los jóvenes en festivales y eventos. No obstante, el mencionado punto crítico de la acción debería estar en su capacidad para el "desarrollo cognitivo de los jóvenes participantes, con estímulos al juicio y la reflexión crítica sobre sus realidades vividas", la cual, de acuerdo con el léxico 
en cuestión y el rasgo freiriano declarado como su directriz más básica, estaría produciendo una humanización en los términos sugeridos por Paulo Freire (Brayner, 2012: 175).

Entretanto, lo que se proclamó como una experiencia inspirada en la Pedagogía del Oprimido en la narrativa de los agentes del MUHNE, fue también precisamente descrito como una actividad de emprendimiento educativo-cultural (Sousa et al., 2015) por agentes interesados en celebrar lo que habría de ser su principal atributo: formar sujetos aptos para insertarse con eficacia en la dinámica del mundo del trabajo. Desde los principios que orientaron la estructuración del contenido programático, pasando por las propias metodologías escogidas y el discurso transversal a toda la acción, resulta evidente que el programa se orienta políticamente a producir ciudadanos que se autorregulen a partir de una ética liberal que los hace sujetos en sintonía con la dinámica contemporánea del Capital. En otras palabras, en lugar de producir individuos autónomos en la línea de Freire, esta iniciativa condujo a una conversión pastoral de sujetos al mundo laboral neoliberal.

Aparte de cierto tipo de dialogismo, diversidad, humanismo y visibilidad, hay muy poco que permita considerar tal acción como liberadora en los términos de Freire. La naturaleza crítica de esta acción es mucho más retórica que objetiva. Ante la necesidad de conferir matices más progresistas a una tarea conservadora, y hacerla aparentar ser políticamente más democrática, la utilización de una formulación que reordena los signos que configuran el pensamiento freiriano para considerarlo menos revolucionario, y más reformista, parece ser una operación bastante eficaz — desde un punto de vista opuesto al del oprimido-. En gran medida, su insistencia sobre los peligros de un falso "ser para sí" (Freire, 1987: 99) parecía vaticinar la importancia y la complejidad de este tipo de problema.

La economía política de esta operación discursiva, que imprime en el quehacer de los museos un compromiso con la transformación social en los términos de Paulo Freire, tiene su base en el interés de la Unesco por potenciar el patrimonio como recurso para el desarrollo. El ICOM, al interesarse por considerar los museos como espacios dialógicos, traduce este deseo de potenciar la diferencia cultural 
como recurso para el desarrollo local, realineando la relación entre museos y comunidades. El sentido de "integral", que define la renovación de la museología, y que nació y fue cultivado en áreas bajo la influencia de la Unesco, sugiere justamente una relación dialógica entre un agente educativo (el museo) y el Otro (la comunidad).

Sin embargo, en lugar de incorporar la integralidad de una crítica materialista en los términos freirianos, la nueva museología la suprime. En su lugar, la transformación adquiere un sentido de acceso a la ciudadanía cultural -la inclusión-donde la diferencia es el elemento estructurador, y su reconocimento, la libertad correspondiente. En este punto, el estar libre deja de referirse a autonomía y humanización, tal como se refería anteriormente, y pasa a significar disponer de un campo de posibilidades para actuar dentro de la democracia. Por lo tanto, la nueva museología se reviste de una capa discursiva que la posiciona como un legítimo proyecto multicultural, cuya praxis debe ser girada hacia la acomodación de los espacios de poder (los museos) con la representación del Otro, al mismo tiempo que aquello que lo define - su diferencia-, es transformado en recurso económico, bajo el signo del patrimonio, para la producción de experiencias de desarrollo que se declaran como interesadas en la producción de una realidad en pro de esas comunidades.

\section{Conclusiones}

En Paulo Freire, el diálogo aparece como instrumento promotor de una experiencia de liberación, siendo este equivalente a la capacidad del sujeto para decidir, hablar y actuar sobre y con la realidad en sus propios términos, y de forma de cambiarla en pro de una sociedad más igualitaria. Sin embargo, se percibe algo más sobre los términos de este diálogo, especialmente en lo que se refiere a la propia posibilidad del individuo de expresar algo por sí y a partir de su subalternidad. Así como hay también algo a tener en cuenta en el poder, que no está ausente, de la relación que se establece entre el agente educativo y el Otro que se humaniza. En ambas posibilidades, el camino por el cual se accede al conocimiento, y la fuerza para 
hablar, implican para el sujeto un uso determinante (pero no coercitivo) de elementos que le son externos, aunque reconocidos y legitimados por aquellos que funcionan como agentes del proceso humanizador.

Gayatri Chakravorty Spivak (2010) se vuelca sobre el hablar como un elemento fundamental para la superación de las condiciones de opresión, y ofrece una buena perspectiva para que se pueda comprender la dimensión política de la centralidad del diálogo en la construcción de la libertad. En su concepción (Gramsciana) de subalternidad, es el hecho de que su voz no se escuche lo que confiere al sujeto la condición de subalterno y oprimido, y no cualquier otra categoría que lo reduzca homogéneamente a esta situación. Hablar, según G. C. Spivak (2014), corresponde a una posición discursiva en la que se presupone la existencia de un hablante y de un oyente, donde tendría que existir una interacción dialógica en la que ambos agentes puedan hacerse entender a partir de sus propias voces. Sin embargo, esta autora entiende que esta es una condición que nunca se da para el sujeto que está en la subalternidad, u oprimido, mientras que sin algún tipo de transacción este nunca conseguirá hablar. Este patrocinio, e intermediación, es lo que define su esencia y le impone códigos que no son suyos en cuanto posibilidad de ser representados, y lo que les priva de la posibilidad de hablar por ellos mismos ${ }^{4}$.

Por otro lado, el diálogo interesado en la escucha y en el patrocinio, especialmente aquel que se edifica a partir de un imperativo de conducir a un Otro a alcanzar alguna verdad, fue entendido por Michel Foucault (1997) como un campo para el ejercicio de una forma de poder que es la matriz de las formas modernas y contemporáneas de estrategias de gobierno: el poder pastoral. Este, que Foucault identifica como fuertemente enraizada en la tradición del cristianismo, depende fundamentalmente de la idea de libertad, mientras que no priva al sujeto de desear, preocupándose por inducir al sujeto a querer y escoger voluntariamente tipos específicos de aspiraciones.

4. Edward Said (2007), en Orientalismo, hizo una crítica magistral de los términos de este diálogo con el Otro que Occidente busca construir. En su análisis, demuestra cómo Occidente (como el polo civilizado) produce la condición política y epistémica de esta conversación. Además, es este polo el que produce el Otro que debe escucharse (bajo el signo de la Diversidad). Para Said, esta relación termina reafirmando la hegemonía occidental, mientras que las posibilidades de este diálogo se construyen a través de su propia razón. 
Al respecto de los reiterados señalamientos que Paulo Freire hace en sus trabajos sobre las posibles contradicciones inherentes al acceso pleno del sujeto a pronunciar la palabra (la invasión cultural), el uso multicultural de su Pedagogía materializa tanto la paradoja señalada por G. C. Spivak (2014) de un patrocinio que produce al Otro en su pretensión (a veces bien intencionada) de hablar por él, como el de una liberación (por el reconocimiento) basada en la individualidad del sujeto que revela una sofisticada conducción voluntaria de su conducta.

Los museos, en cuanto instituciones que se relacionan con las comunidades, producen aquello que declaran representar al seleccionar los rasgos que las definen, e inevitablemente silencian y mantienen invisibles las diferencias que no son computadas en sus carteras como partes de la diversidad. Su promoción de una experiencia dialógica, así como sugiere G. C. Spivak (2014), no se da al margen de su racionalidad institucional, lo que hace del diálogo en estos términos un expediente sin plenitud de voz y de palabra por parte del oprimido, e incapaz de producir políticamente la autonomía que Freire idealizó. Además de esto, este dialogismo es también siempre una posibilidad de regulación del Otro, mientras que el discurso en el museo está condicionado por aquello que el museo concibe como lo oprimido que debe ser liberado. Esta mediación del museo, entre el sujeto y el acceso al derecho cultural, es fundamentalmente donde se materializa una política cultural pautada por una lógica de gobierno de las personas, y que produce ciudadanos moralmente comprometidos con el orden que les disputa el derecho a hablar.

Aunque todo esto se haya demostrado a partir del contexto brasileño, esa política cultural se inserta en un espectro mucho más global; las discrepancias de sentido — tal como ha ocurrido con Paulo Freire y la nueva museología- a fin de conferir un empaque progresista a dispositivos políticamente conservadores son un expediente muy propio de la razón neoliberal (Bourdieu \& Wacquant, 2002). Es esto lo que considero el núcleo de todos los reordenamientos discursivos producidos bajo la pedagogía freiriana, mientras que esa razón encuentra en el agotamiento de definiciones - que, no por casualidad, son muy apreciadas para Paulo Freire, tales como explotación, capitalismo, emancipación, clase, y tantas otras que remiten a 
su crítica materialista - una estrategia fundamental para conferir tácticamente a sus prácticas neoliberales el sentido de una política que supera toda esa agenda "obsoleta", y se atiene a lo que verdaderamente importa, sin dejar de ser progresista.

Sin embargo, la ciudadanía producida por esta política cultural —así como el propio neoliberalismo - viene dando muestras de su agotamiento, siendo uno de sus efectos más perceptibles el reciente aumento en la temperatura de las guerras culturales brasileñas. La insuficiencia de la democracia multicultural para garantizar el acceso a otros Derechos y superar desigualdades trajo al centro del debate político importantes símbolos de sus políticas, los cuales son utilizados por la extrema derecha brasileña para producir una crítica reaccionaria que les atribuye la responsabilidad por las contradicciones históricas del Estado - más específicamente relacionadas con la Educación-. Es este el diseño de la crítica que se popularizó en relación con Paulo Freire.

Esta, no obstante, deja a aquellos interesados en defender el legado de Freire una tarea compleja, que es la de criticar simultáneamente las adaptaciones que le confirieron sentidos externos a su proyecto - y que están cubiertos todavía de una manta discursiva que los considera aliados y liberadores- y de rehabilitar la pujanza crítica y anticapitalista que la enunciación multicultural y desarrollista invisibilizó en favor de hacer dócil su ideario. En este sentido, el enunciado (plenamente verdadero) que se contrapone a esta crítica, el que afirma que el pensamiento de Paulo Freire nunca se materializó como política adoptada por el Estado Brasileño, necesita ser pulido a fin de que se muestre la naturaleza materialista (crítica), radical, revolucionaria y aun urgente de su pensamiento, así como los problemas que crea su reducción a una teoría de la diversidad y sustentabilidad económica. 


\section{Bibliografía}

- BENNETT, T. (2013). The birth of the museum: History, theory, politics. London and New York: Routledge.

- BOURDIEU, P. \& WACQUANT, L. (2002). Sobre as artimanhas da razão imperialista. Estudos afro-asiáticos, 24(1), 15-33.

- BRAYNER, V. (2012). “Desenvolvi-gente”: o jovem artesão do Museu do Homem do Nordeste, em Araçoiaba (PE) e a dimensão antropológica das políticas públicas de cultura no Brasil (Dissertação de Mestrado). Programa de Pós-graduação em Antropologia da Universidade Federal de Pernambuco, Recife.

- BRULON, B. (2019). A History of Museology. Key Debates in Museological Theory. Paris: ICOFOM.

- CHAGAS, M. \& GOUVEIA, I. (2014). Museologia social: reflexões e práticas (à guisa de apresentação). Revista Cadernos do Ceom, 27(41), 9-22.

- DUARTE, A. (2014). Nova museologia: os pontapés de saída de uma abordagem ainda inovadora. Revista Museologia e Patrimônio, 6(2), 99-117.

- DERRIDA, J. (2001). On Cosmopolitanism and Forgiveness. London and New York: Routledge.

- FOUCAULT, M. (1997). The politics of truth. New York: Semiotext(e).

- FREIRE, P. (1981). Ação cultural para a liberdade. Rio de Janeiro: Paz e Terra.

- FREIRE, P. (1987). Pedagogia do Oprimido. Rio de Janeiro: Paz e Terra.

- FUNDAÇÃO JOAQUIM NABUCO. (2012). Relatório de gestão do exercício 2011. Recuperado de https://www.fundaj.gov.br/images/institucional/ relgestao2011.pdf

- FUNDAÇÃO JOAQUIM NABUCO. (2010). Relatório de gestão do exercício 2009. Recuperado de https://www.fundaj.gov.br/geral/rg/relatorio_gestao2009.pdf

- HEGEL, G. W. F. (1992). Fenomenologia do espírito. Petrópolis: Vozes. 
- HEIDEGGER, M. (2007). A questão da técnica. Scientiae Studia, 5(3), 375-398.

- INSTITUTO BRASILEIRO DE MUSEUS. (2007). Política Nacional de Museus. Recuperado de https://www.museus.gov.br/wp-content/uploads/2010/01/ politica_nacional_museus.pdf

- INSTITUTO BRASILEIRO DE MUSEUS. (2012a). Mesa redonda sobre la importancia y el desarrollo de los museos en el mundo contemporáneo: Mesa Redonda de Santiago de Chile, 1972. Recuperado de http://www.ibermuseus. org/wp-content/uploads/2014/09/Publicacion_Mesa_Redonda_VOL_I.pdf

- INSTITUTO BRASILEIRO DE MUSEUS. (2012b). Educação museal: experiências e narrativas (Prêmio Darcy Ribeiro 2008). Recuperado de https://www.museus. gov.br/wp-content/uploads/2016/11/premio_2008.pdf

- INSTITUTO BRASILEIRO DE MUSEUS. (2018). Caderno da Política Nacional de Educação Museal. Recuperado de https://www.museus.gov.br/wp-content/ uploads/2010/01/politica_nacional_museus.pdf

- LEHER, R. \& MOTTA, V. C. (2012). Políticas educacionais neoliberais e educação do campo. En R. S. CALDART et al. (Ed.). Dicionário da educação do campo (pp. 578-587). São Paulo: Expressão Popular.

- LIMA, G. G. F. \& NETO, H. M. (2019). Economia criativa, patrimônio e diversidade: o Paço do Frevo e o neoconservadorismo nas políticas culturais. Patrimônio e Memória, 15(1), 449-473.

- MARTINI, R. R. (2009). Os intelectuais do iseb, cultura e educação nos anos cinqüenta e sessenta. Revista Aurora, 3(1), 59-67.

- MILlER, T. \& YÚDICE, G. (2002). Cultural Policy. London: Sage.

- NOGUEIRA, A. S. (1997). Educação: preparação para o século XXI. Obra de Paulo Freire; Série Diálogos. Recuperado de http://acervo.paulofreire.org:8080/ jspui/bitstream/7891/1365/1/FPF_OPF_05_001.pdf

- SAID, E. W. (2007). Orientalismo: o Oriente como invenção do Ocidente. São Paulo: Editora Companhia das Letras. 
- SANTOS, M. C. T. M. (2014). Um compromisso social com a museologia. Revista Cadernos do Ceom, 27(41), 71-114.

- SCHEINER, T. C. (2012). Repensando o Museu Integral: do conceito às práticas. Boletim do Museu Paraense Emílio Goeldi. Ciências Humanas, 7(1), 15-30.

- SILVA, T. T. (2000). A produção social da identidade e da diferença. En T. T. SILVA (Ed), Identidade e diferença: a perspectiva dos estudos culturais. (pp. 73102) Petrópolis: Vozes.

- SOUSA, J. L., PAIVA JÚNIOR, F. G. \& XAVIER FILHO, J. L. J. (2015). A emergência do empreendedorismo educativo-cultural: o Programa de Formação do Jovem Artesão. Administração Pública e Gestão Social, 7(1), 45-52.

- SPIVAK, G. C. (2010). Pode o subalterno falar?. Belo Horizonte: Editora UFMG.

- VARINE, H. (1996). Apresentação. (entrevista concedida à Mário Chagas). Cadernos de Museologia, 5, 5-18.

- VARINE, H. (2000). Autour de la table ronde de Santiago. Culture \& Musées, 17(1), 180-183.

- VARINE, H. (2013). As raízes do futuro: o patrimônio a serviço do desarrollo local. Porto Alegre: Medianiz.

- YÚDICE, G. (2006). A conveniência da cultura: usos da cultura na era global. Belo Horizonte: Ed. UFMG. 


\section{Biografía}

\section{Glauber de Lima}

Universidade Federal de Goiás - UFG (Brasil)

ORCID: 0000-0001-5332-6731

delimaglauber@gmail.com

Máster y licenciatura en Historia, y profesor adjunto en el Departamento de Museología de la Universidad Federal de Goiás (UFG), Goiânia, Brasil. Sus intereses de investigación incluyen temas de política cultural, revitalización urbana, economía de la cultura, patrimonio y museos. En su trabajo se ha interesado en producir una lectura crítica de la articulación entre multiculturalismo, inclusión, desarrollo y política cultural en el contexto brasileño. Actualmente desarrolla una investigación doctoral sobre ciudadanía cultural en Brasil en el Instituto de Medios e Industrias Creativas de la Universidad de Loughborough, Londres, Reino Unido. 